\title{
Relationship Between Cancer Type and Impact of PET and PET/CT on Intended Management: Findings of the National Oncologic PET Registry
}

\author{
Bruce E. Hillner ${ }^{1,2}$, Barry A. Siegel ${ }^{3,4}$, Anthony F. Shields ${ }^{5}$, Dawei Liu ${ }^{6}$, Ilana F. Gareen ${ }^{6}$, Ed Hunt ${ }^{6}$, \\ and R. Edward Coleman ${ }^{7}$ \\ ${ }^{1}$ Department of Internal Medicine, Virginia Commonwealth University, Richmond, Virginia; ${ }^{2}$ Massey Cancer Center, Virginia \\ Commonwealth University, Richmond, Virginia; ${ }^{3}$ Division of Nuclear Medicine, Mallinckrodt Institute of Radiology, School of Medicine, \\ Washington University, St. Louis, Missouri; ${ }^{4}$ Siteman Cancer Center, School of Medicine, Washington University, St. Louis, Missouri; \\ ${ }^{5}$ Karmanos Cancer Institute, Wayne State University, Detroit, Michigan; ${ }^{6}$ Center for Statistical Sciences, Brown University, Providence, \\ Rhode Island; and ${ }^{7}$ Department of Radiology, School of Medicine, Duke University, Durham, North Carolina
}

\begin{abstract}
We previously reported aggregate data showing that PET was associated with a change in intended management for over one third of patients participating in the National Oncologic PET Registry (NOPR). Here, we present results for specific cancer types and indications for testing. Methods: The NOPR collected questionnaire data from referring physicians on intended management before and after PET. Data were available from 40,863 PET studies done at 1,368 centers. The impact of PET was assessed for 18 cancer types in patients with pathologically confirmed cancer by type and indication for testing (initial staging, restaging, or detection of suspected recurrence), other than treatment monitoring. Results: When intended management was classified as treatment or nontreatment, physicians changed their intended management for $38.0 \%$ of cases $(95 \%$ confidence interval $=37.6 \%-38.5 \%$ ). The frequencies of changes in management ranged from $48.7 \%$ for myeloma to $31.4 \%$ for nonmelanoma skin cancer. Comparisons across testing indications revealed that only in multiple myeloma did PET have a consistently greater impact on intended management. When the intended management plan before PET was treatment, a change in the intent of treatment (curative vs. palliative) or a major change in the modality of treatment occurred at similar frequencies across different cancer types. Conclusion: The impact of PET on physicians' intended management for patients with known cancer was consistent across cancer types.
\end{abstract}

Key Words: PET; cancer; registry; prospective studies

J Nucl Med 2008; 49:1928-1935

DOI: 10.2967/jnumed.108.056713

\section{$\mathbf{P}$} collectively referred to as PET) and performed with the

\footnotetext{
Received Aug. 7, 2008; revision accepted Sep. 9, 2008.

For correspondence or reprints contact: Bruce E. Hillner, Virginia Commonwealth University, 1101 E. Marshall St., Room 7013, Richmond, VA 23298-0170.

E-mail: Hillner@vcu.edu

COPYRIGHT @ 2008 by the Society of Nuclear Medicine, Inc.
}

radiopharmaceutical ${ }^{18} \mathrm{~F}$-FDG is a molecular imaging technique that assesses regional glucose metabolism (1). In clinical practice, ${ }^{18}$ F-FDG PET is most widely used for the imaging of patients with cancer. Currently, the Centers for Medicare \& Medicaid Services (CMS) provides coverage for PET performed on Medicare beneficiaries for 9 common malignancies (2). In 2005, the CMS established a new coverage policy, called "coverage with evidence development" $(2,3)$, to expand the evidence base for evaluating selected promising technologies, including PET for noncovered indications. In response to this policy change, the National Oncologic PET Registry (NOPR) was developed to collect data on the clinical utility of PET to meet requirements for coverage with evidence development (4). The NOPR opened in May 2006.

We recently reported aggregate results from the first year of data collected by the NOPR on the impact of the use of PET for cancer diagnosis, initial staging, restaging, or detection of suspected recurrences of previously noncovered cancers in Medicare beneficiaries (5). Overall, we found that the impact of PET on intended management for these previously noncovered cancers was similar to that previously reported for covered cancers. For the purposes of guiding clinical practice and shaping coverage policy, it is important to determine the relative effects of PET for different cancer types and indications for testing. In this article, we report results by cancer type for the first $2 \mathrm{y}$ of data collected by the NOPR from 40,863 PET scans. We restricted our analysis to the use of PET for staging, restaging, or detection of suspected recurrences in patients with pathologically proven cancers.

\section{MATERIALS AND METHODS}

The NOPR is a prospective data registry that collects information from the PET facility, from the physician requesting the PET scan, and from the interpreting physician's PET report. Detailed descriptions of NOPR operations and human subject protection 
procedures were reported previously $(6,7)$. Submission of data to the registry is required by CMS as a condition for coverage. All data are entered by participating PET facilities via a secure Webbased interface and are stored at the American College of Radiology. The NOPR home page and Web application, including all forms, are located at http://www.cancerPETregistry.org/.

In brief, the PET facility is responsible for collecting information from the referring physician on a "pre-PET" form and a "post-PET form." The pre-PET form focuses on information regarding the specific indication for testing; the patient's cancer type (if known) and working stage assessment; the patient's performance status; whether the referring physician will also be the treating physician; and the referring physician's management plan if PET were not available. Once a PET scan has been completed, the PET facility uploads the PET report to the database. The final step is the completion of the post-PET form by the referring physician to assess the management plan in light of the PET findings.

Data collection is conducted in accordance with a protocol approved by the American College of Radiology Institutional Review Board. The research database consists only of cases in which both patient and physician have given consent.

\section{Outcomes}

As we reported previously (5), the primary endpoint was the impact of PET on physicians' intended management. Intended management was dichotomized as either treatment (e.g., surgery, chemotherapy, radiation, or other treatment, alone or in combination) or nontreatment (e.g., observation, noninvasive imaging, biopsy, or supportive care). A change in management was defined as a switch from treatment to nontreatment or vice versa. In our previous report (5), we noted that PET led to a change in intended management in $36.5 \%$ of cases; a switch from treatment to nontreatment was 3-fold more likely than the converse.

The inclusion of cases for which the plan before PET was imaging may have overestimated the impact of PET. Specifically, it is possible that, if these patients had alternatively undergone another type of imaging (e.g., CT or MRI), the management plan after that imaging would have been the same as the management plan after PET. To address this concern, we performed a sensitivity analysis in which all cases for which the initial management plan was additional imaging were considered to have no change in management. Specifically, cases in which the plan before PET was another type of imaging and the plan after PET was treatment were excluded from the numerator but included in the denominator in calculating the frequency of a management change. We believe that the resulting estimate represents a lower boundary of the impact of PET on intended management with respect to our primary endpoint. This calculated frequency was subsequently referred to as the "imaging-adjusted impact."

Alternative endpoints also were assessed as previously reported (5). These approaches assessed how often the intent of planned therapies changed from curative to palliative (or vice versa) or how often a change in the type of therapy or the number of therapies (as an indirect indicator of care intensity) occurred.

\section{Statistical Analysis}

A change in intended management after PET was modeled as a binary variable on the basis of a binomial distribution. Changes were defined at the PET scan level and were assumed to be independent for different patients, cancer types, or indications for testing. A total of $13.6 \%$ of patients in the cohort (see later discussion) had 2 or more scans; however, because almost all of the multiple scans were obtained for different indications in the cancer care continuum (initial staging, restaging, or detection of suspected recurrence) over a potential 2-y period, they were treated as independent scans.

Changes in the intended management plan were analyzed for each cancer type and specific indication for testing. Only combinations of cancer types and indications with at least 200 cases were separately reported; cancer types with at least 500 cases across all indications also were separately reported. An association between 2 binary variables was quantified with an odds ratio, which was constructed by removing a base group from the entire cohort and then comparing changes in that base group with changes in the remaining cases in the cohort. For example, a change in management for prostate cancer was compared with that for all nonprostate cancers. When multiple testing was involved, a Bonferroni correction was applied to the $P$ values. All $95 \%$ confidence intervals (CI) were 2-sided and were calculated with gaussian approximation. All statistical analyses were performed with SAS version 9.1 (SAS Institute Inc.).

\section{RESULTS}

\section{Definition of Cohort}

Figure 1 shows how the 2-y NOPR cohort was defined for this analysis. By definition, all patients were Medicare beneficiaries. The NOPR began accepting patients on May 8, 2006. As of May 7, 2008, 81,951 PET studies were registered, had complete data submitted, and were potentially eligible for inclusion (Fig. 1). Of these, 9,644 cases (11.8\%) were excluded because the patients or the referring physicians did not consent to the use of their data for research purposes. Another 4,352 cases (5.3\%) were excluded because the PET study appeared to have been requested for a cancer type and indication already covered or specifically not covered by Medicare (2).

For this analysis of the impact of PET for specific cancer types, only patients with histologically confirmed cancers of known origins and undergoing PET for initial staging, restaging, or detection of suspected recurrences were included. Therefore, we excluded cases in which PET was performed for cancer diagnosis, including cancer of unknown primary origin, or for monitoring of a response to treatment during a planned course of chemotherapy or radiotherapy. In addition, we also excluded 1,263 cases in which PET was requested for initial staging, restaging, or detection of suspected recurrences but the referring physician indicated that the cancer was not pathologically confirmed.

The final analysis cohort thus consisted of 40,863 scans performed in 34,536 patients; 14,365 scans were for initial staging of newly diagnosed cancer, 14,584 scans were for restaging of cancer after completion of a course of treatment, and 11,914 scans were for the evaluation of a suspected recurrence of a previously treated cancer.

\section{Participating Centers and Patient Profiles}

Table 1 summarizes the cohort demographics. The mean patient age was $72.4 \mathrm{y}$. There were nearly equal numbers of 


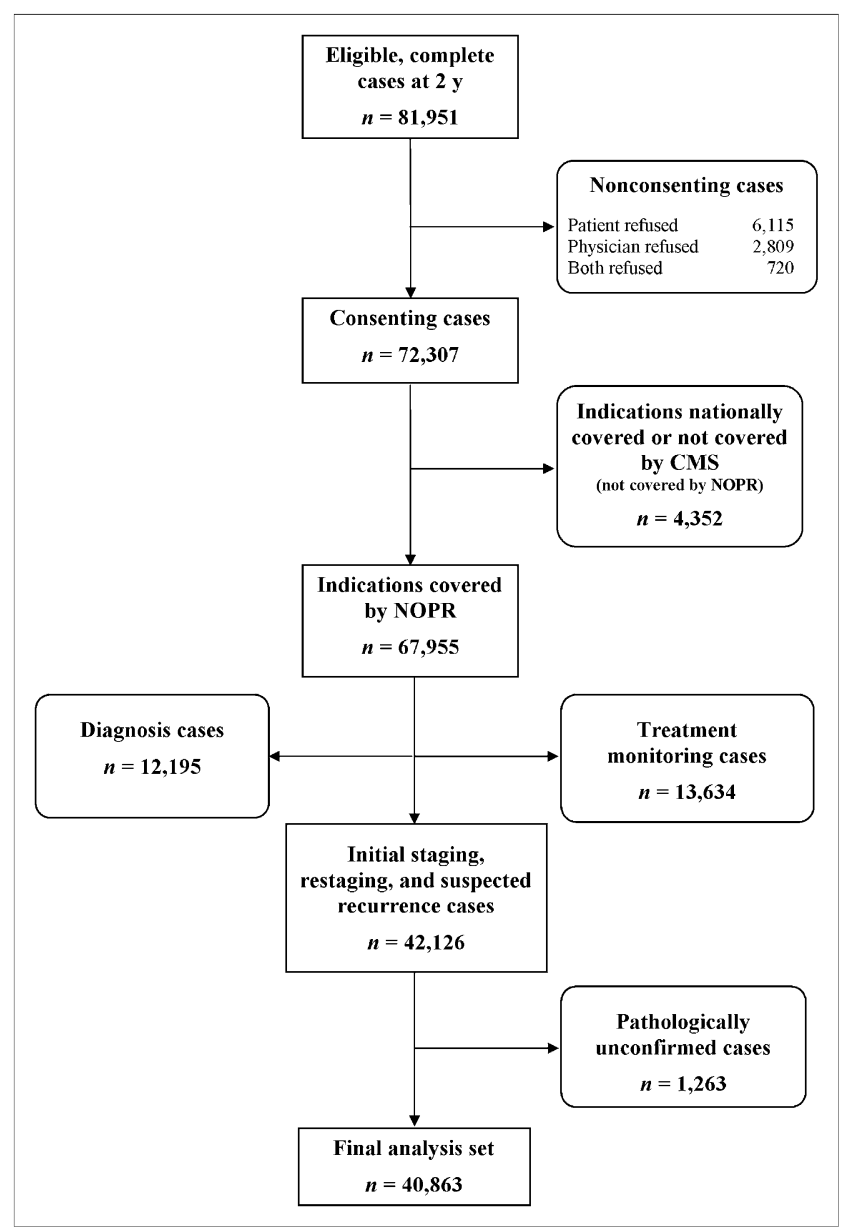

FIGURE 1. Development of 2-y NOPR cohort (see text for details). Numbers represent PET scans, not individuals having scans.

men and women. Most patients (88.2\%) had an Eastern Cooperative Oncology Group performance status of 0 or 1 . The summary cancer stage before PET was judged as no evidence of disease in $12.0 \%$ of cases, locoregional disease in $33.5 \%$, metastatic disease in $29.4 \%$, and unknown or uncertain in $25.1 \%$. Most of the scans $(88.7 \%)$ were obtained with a PET/CT scanner. Patients were enrolled from 1,368 PET centers across the United States. As noted earlier, 34,536 patients participated; $86.4 \%$ of patients had a single scan, and $13.6 \%$ had 2 or more scans.

\section{Impact on Treatment and Nontreatment Decisions}

Table 2 shows the impact of PET on intended management overall and stratified by cancer type. Overall, PET led to a change in intended management from treatment to nontreatment or vice versa in $38.0 \%$ (95\% CI $=37.6 \%-38.5 \%)$ of cases. Among the 4,704 patients (13.6\%) who had at least 2 PET scans, the frequency of a change in intended management with the first scan $(39.2 \%$ [95\% CI $=37.8 \%-40.6 \%])$ was slightly but significantly higher than that with the second scan $(6.2 \%$ [95\% CI $=34.8 \%-37.6 \%])$. Among the 1,167 patients who had 3 or more scans, the value for the third or subsequent scans was approximately $34 \%$. The fraction of
TABLE 1

NOPR Cohort Characteristics

\begin{tabular}{|c|c|}
\hline Characteristic & Value \\
\hline \multicolumn{2}{|l|}{ Age, y } \\
\hline Mean & 72.4 \\
\hline Interquartile range $(25 \%-75 \%)$ & $68-78$ \\
\hline$<65$ & $4,120(10.1)$ \\
\hline$>85$ & $2,123(5.2)$ \\
\hline Females/males, \% & $50.2 / 49.8$ \\
\hline \multicolumn{2}{|l|}{ No. of scans, no. (\%) of patients } \\
\hline One & $29,832(86.4)$ \\
\hline Two or more & $4,704(13.6)$ \\
\hline \multicolumn{2}{|l|}{ ECOG performance category (status) } \\
\hline Asymptomatic: fully active (0) & 16,188 (39.6) \\
\hline Symptomatic, fully ambulatory (1) & $19,868(48.6)$ \\
\hline Symptomatic in bed $<50 \%$ of day (2) & $3,721(9.1)$ \\
\hline Symptomatic in bed $>50 \%$ of day (3) & $1,007(2.5)$ \\
\hline Bedridden (4) & $79(0.2)$ \\
\hline \multicolumn{2}{|l|}{ Summary cancer stage before PET } \\
\hline No evidence of disease & $4,914(12.0)$ \\
\hline Localized only & $8,036(19.7)$ \\
\hline $\begin{array}{l}\text { Regional, by direct extension or } \\
\text { lymph node involvement }\end{array}$ & $5,630(13.8)$ \\
\hline $\begin{array}{l}\text { Metastatic (distant), with single } \\
\text { suspected site }\end{array}$ & $5,043(12.3)$ \\
\hline $\begin{array}{l}\text { Metastatic (distant), with multiple } \\
\text { suspected sites }\end{array}$ & $6,984(17.1)$ \\
\hline Unknown or uncertain & $10,256(25.1)$ \\
\hline \multicolumn{2}{|l|}{ Scan type and facility location, \% } \\
\hline Integrated PET/CT & 88.7 \\
\hline Non-hospital-based location & 68.9 \\
\hline Fixed location & 74.7 \\
\hline \multicolumn{2}{|c|}{$\begin{array}{l}\text { ECOG = Eastern Cooperative Oncology Group. } \\
\text { Results are reported as number (percentage) of scans unless } \\
\text { otherwise indicated. }\end{array}$} \\
\hline
\end{tabular}

patients who had 2 or more scans was notably higher than average for ovarian cancer (19.5\%) and myeloma (17.7\%) and notably lower than average for prostate cancer $(6.0 \%)$ and liver cancer (7.2\%).

There were 16 cancer types with at least 500 cases in the cohort. These are listed in Table 2, in order of descending frequency, along with the frequency of a change in intended treatment or nontreatment after PET, the odds ratio for a change in management for each specific cancer compared with other cancers, the frequency of alternative imaging as the plan before PET, and the imaging-adjusted impact on intended management.

The frequency of a change in intended management by cancer type ranged from a low of $31.4 \%$ for nonmelanoma skin cancers to a high of $48.7 \%$ for myeloma. The frequency of a change in intended management for 7 of the 16 cancer types differed significantly from that for all other types, as indicated by the odds ratio. Myeloma was the only cancer type among these 7 with an odds ratio (1.58) that was notably different from 1.0.

Table 2 also shows the imaging-adjusted impact of PET on intended management. Overall, the imaging-adjusted impact 
TABLE 2

Impact of PET on Intended Management by Cancer Type*

\begin{tabular}{|c|c|c|c|c|c|c|c|c|}
\hline Cancer type & $\begin{array}{l}\text { No. of } \\
\text { scans }\end{array}$ & $\begin{array}{c}\% \text { of cases } \\
\text { with change in } \\
\text { management }^{\dagger}\end{array}$ & $95 \% \mathrm{Cl}$ & $\begin{array}{l}\text { Odds ratio } \\
\text { for change in } \\
\text { management } \\
\text { compared with } \\
\text { that for other } \\
\text { cancers }^{\ddagger}\end{array}$ & $95 \% \mathrm{Cl}$ & $\begin{array}{c}\text { Frequency of } \\
\text { other imaging } \\
\text { as plan before } \\
\text { PET (\%) }\end{array}$ & $\begin{array}{l}\text { Imaging-adjusted } \\
\text { impact }(\%)^{\S}\end{array}$ & $95 \% \mathrm{Cl}$ \\
\hline Prostate & 5,309 & 35.1 & $33.8-36.4$ & $0.86 \|$ & $0.81-0.92$ & 39.9 & 15.0 & $14.1-16.0$ \\
\hline Ovary & 4,509 & 41.4 & $40.0-42.9$ & $1.17^{\|}$ & $1.10-1.25$ & 52.1 & 16.2 & $15.1-17.3$ \\
\hline Bladder & 3,578 & 37.9 & $36.3-39.5$ & $0.99 \pi$ & $0.93-1.07$ & 45.1 & 15.4 & $14.2-16.6$ \\
\hline Pancreas & 3,314 & 39.0 & $37.3-40.6$ & $1.04 \pi$ & $0.97-1.12$ & 42.7 & 14.8 & $13.6-16.1$ \\
\hline Stomach & 3,025 & 36.9 & $35.2-38.6$ & 0.95 & $0.88-1.03$ & 45.2 & 14.5 & $13.2-15.7$ \\
\hline Small cell lung & 2,983 & 41.2 & $39.5-43.0$ & $1.16^{\#}$ & $1.07-1.25$ & 49.7 & 13.1 & $11.9-14.3$ \\
\hline Kidney & 2,877 & 35.8 & $34.0-37.6$ & 0.901 & $0.83-0.98$ & 48.9 & 16.0 & $14.7-17.4$ \\
\hline Uterus & 2,869 & 36.5 & $34.7-38.2$ & 0.939 & $0.86-1.01$ & 47.6 & 15.1 & $13.8-16.4$ \\
\hline Myeloma & 1,784 & 48.7 & $46.3-51.0$ & $1.58 \|$ & $1.43-1.73$ & 61.3 & 11.5 & $10.0-13.0$ \\
\hline Connective tissue & 1,350 & 36.4 & $33.8-38.9$ & 0.93 & $0.83-1.04$ & 49.9 & 13.6 & $11.8-15.5$ \\
\hline Nonmelanoma skin & 1,057 & 31.4 & $28.6-34.2$ & $0.74^{\#}$ & $0.65-0.84$ & 49.8 & 9.6 & $7.9-11.4$ \\
\hline $\begin{array}{l}\text { Liver and intrahepatic } \\
\text { bile ducts }\end{array}$ & 1,038 & 42.9 & $39.9-45.9$ & 1.239 & $1.08-1.39$ & 44.3 & 15.8 & $13.6-18.0$ \\
\hline Cervix & 984 & 32.7 & $29.8-35.7$ & $0.79^{\#}$ & $0.69-0.90$ & 48.4 & 11.9 & $9.9-13.9$ \\
\hline Gallbladder & 806 & 39.7 & $36.3-43.1$ & 1.079 & $0.93-1.24$ & 43.8 & 15.4 & $12.9-17.9$ \\
\hline Other female genital & 709 & 37.1 & $33.5-40.7$ & 0.96 I & $0.82-1.12$ & 41.9 & 13.0 & $10.5-15.4$ \\
\hline Thyroid & 629 & 35.6 & $31.9-39.4$ & $0.90 \AA$ & $0.76-1.06$ & 53.6 & 13.4 & $10.7-16.0$ \\
\hline All other & 4,042 & 36.6 & $35.1-38.1$ & $0.93 \pi$ & $0.87-1.00$ & 49.2 & 15.7 & $14.5-16.8$ \\
\hline Total & 40,863 & 38.0 & $37.6-38.5$ & NA & NA & 47.3 & 14.7 & $14.3-15.0$ \\
\hline \multicolumn{9}{|c|}{$\begin{array}{l}\text { *Specific cancer types are listed when there were at least } 500 \text { cases for initial staging, restaging, and detection of suspected recurrenc } \\
\text { ombined. } \\
{ }^{\dagger} \text { Defined as change from treatment to nontreatment or as change from nontreatment to treatment. } \\
\text { "Odds ratio of } 1 \text { implies that chance of changing management is equal between an individual cancer and all other cancer groups. Odd } \\
\text { tio }<1 \text { implies that chance of changing management is lower for the individual cancer than for all the others. Odds ratio }>1 \text { implies tha } \\
\text { רance of changing management is higher for an individual cancer than for all the others. NA = not applicable. } \\
\S^{\S} \text { No benefit from PET was assumed for cases with imaging plan before PET. } \\
\text { "Bonferroni-adjusted } \chi^{2} P \text { value for chance of change in management was }<10^{-4} \text {. } \\
\text { "Bonferroni-adjusted } \chi^{2} P \text { value for chance of change in management was between } 0.01 \text { and } 1.0 \text {. } \\
\text { "Bonferroni-adjusted } \chi^{2} P \text { value for chance of change in management was between } 0.0001 \text { and } 0.01 \text {. }\end{array}$} \\
\hline
\end{tabular}

of PET was $14.7 \%(95 \% \mathrm{CI}=14.3 \%-15.0 \%)$; the cancerspecific values varied relatively little, ranging from a low of $9.6 \%$ for nonmelanoma skin cancers to $16.2 \%$ for ovarian cancer. The imaging-adjusted impact of PET for myeloma (11.5\%) was lower than the average for all cancers.

Table 3 shows that, as previously reported, a change from nontreatment to treatment was substantially more likely than a change from treatment to nontreatment $(30.0 \%$ vs. $8.0 \%$ overall), and this was true across all cancer types. Table 3 also shows modifications in intended management when the plan before PET was treatment. A change in the goal of treatment from curative to palliative (or vice versa) occurred in $14.1 \%$ of cases overall, with relatively little variation as a function of cancer type (range $=10.0 \%-18.2 \%$ ). In $15.1 \%$ of cases (range $=7.3 \%-20.7 \%$ ), when treatment was planned before PET, the plan after PET was changed to either supportive care or observation; this change occurred most often in cancer of the kidney and least often in other female genital cancers. A major change in planned treatment (e.g., from surgery to chemotherapy) occurred in $8.6 \%$ of cases overall (range $=5.1 \%-14.7 \%)$, most often in tumors of the liver and intrahepatic bile ducts and least often in myeloma and nonmelanoma skin cancers. A minor change in planned treatment (e.g., the addition or deletion of a mode of therapy) was more common (23.3\% of cases overall) and occurred most frequently in cervical cancer $(34.7 \%)$ and least frequently in myeloma $(9.7 \%)$.

\section{Testing Indications}

Table 4 shows the aggregated results for all cancers stratified by testing indication. PET was associated with essentially equivalent changes in intended management for the testing indications: $39.8 \%$ of cases for initial staging, $35.9 \%$ for restaging, and $38.5 \%$ for detection of suspected recurrences. On the basis of the imaging-adjusted impact, however, the impact of PET was significantly greater when PET was performed for detection of suspected recurrences $(18.8 \%$; odds ratio $=1.56)$ than when it was performed for initial staging $(13.4 \%)$ or restaging (12.6\%). For each testing indication, the frequency of a change in intended 
TABLE 3

Details and Alternative Endpoints of Impact of PET on Intended Management by Cancer Type*

\begin{tabular}{|c|c|c|c|c|c|c|c|}
\hline \multirow[b]{3}{*}{ Cancer type } & \multirow{2}{*}{\multicolumn{3}{|c|}{ Change in management details }} & \multicolumn{2}{|c|}{ Change in treatment goals } & \multicolumn{2}{|c|}{ Change in treatment modes } \\
\hline & & & & \multirow{2}{*}{$\begin{array}{l}\text { Change } \\
\text { in goal } \\
\text { of original } \\
\text { treatment } \\
\text { plan }\end{array}$} & \multirow{2}{*}{$\begin{array}{l}\text { Change from } \\
\text { treatment to } \\
\text { supportive care } \\
\text { or observation }\end{array}$} & \multirow{2}{*}{$\begin{array}{l}\text { Major change } \\
\text { in type of } \\
\text { treatment } \\
\text { relative to plan } \\
\text { before PET }\end{array}$} & \multirow{2}{*}{$\begin{array}{l}\text { Minor change } \\
\text { in type of } \\
\text { treatment } \\
\text { relative to plan } \\
\text { before PET }\end{array}$} \\
\hline & $\begin{array}{l}\text { Nontreatment } \\
\text { to treatment }\end{array}$ & $\begin{array}{l}\text { Treatment to } \\
\text { nontreatment }\end{array}$ & $\begin{array}{l}\text { Odds } \\
\text { ratio }^{\dagger}\end{array}$ & & & & \\
\hline Prostate & 25.3 & 9.7 & 4.3 & 12.9 & 13.7 & 8.5 & 12.1 \\
\hline Ovary & 34.2 & 7.2 & 3.1 & 12.5 & 19.2 & 6.4 & 19.2 \\
\hline Bladder & 29.9 & 8.0 & 4.0 & 15.7 & 13.8 & 9.1 & 26.7 \\
\hline Pancreas & 31.2 & 7.8 & 3.8 & 16.9 & 13.5 & 8.6 & 26.5 \\
\hline Stomach & 28.2 & 8.7 & 4.0 & 16.0 & 14.4 & 8.6 & 31.5 \\
\hline Small cell lung & 34.9 & 6.3 & 3.9 & 13.9 & 13.2 & 7.4 & 28.6 \\
\hline Kidney & 27.7 & 8.1 & 3.8 & 12.6 & 20.7 & 9.7 & 19.2 \\
\hline Uterus & 28.9 & 7.6 & 4.4 & 13.8 & 15.9 & 9.8 & 27.4 \\
\hline Myeloma & 41.7 & 7.0 & 2.2 & 11.7 & 20.3 & 5.3 & 9.7 \\
\hline Connective tissue & 29.7 & 6.7 & 4.9 & 12.4 & 11.8 & 10.1 & 29.0 \\
\hline Nonmelanoma skin & 25.5 & 5.9 & 7.7 & 10.0 & 8.9 & 5.1 & 31.7 \\
\hline $\begin{array}{l}\text { Liver and intrahepatic } \\
\text { bile ducts }\end{array}$ & 33.6 & 9.2 & 2.6 & 18.2 & 10.8 & 14.7 & 23.7 \\
\hline Cervix & 25.4 & 7.3 & 5.9 & 13.5 & 13.8 & 7.4 & 34.7 \\
\hline Gallbladder & 31.5 & 8.2 & 3.5 & 17.8 & 12.6 & 10.4 & 22.1 \\
\hline Other female genital & 30.0 & 7.1 & 4.5 & 15.1 & 7.3 & 8.3 & 34.5 \\
\hline Thyroid & 26.4 & 9.2 & 3.8 & 14.7 & 16.1 & 11.5 & 26.0 \\
\hline All other & 27.6 & 9.0 & 3.7 & 14.5 & 20.0 & 8.9 & 22.6 \\
\hline Total & 30.0 & 8.0 & 3.9 & 14.1 & 15.1 & 8.6 & 23.3 \\
\hline
\end{tabular}

*Specific cancer types are listed when there were at least 500 cases for initial staging, restaging, and detection of suspected recurrence combined.

${ }^{\dagger}$ Odds ratios compare chance of having plan for treatment after PET with chance of having plan for treatment before PET. Because more participants had treatment plans after PET than before PET, values were consistently higher than one.

Except for odds ratios, data are reported as percentages of cases.

management with PET/CT was slightly but not significantly greater than that with PET alone (data not shown).

Initial Staging. Table 5 summarizes the impact of PET on intended management for initial staging by cancer type. Prostate cancer was the most common cancer type in the initial staging subgroup. The impacts of PET by cancer type were tightly clustered, except that the impact was lower in patients with prostate cancer $(32.0 \%$; odds ratio $=$ $0.67)$ and higher in those with myeloma (52.2\%; odds ratio $=$ 1.68). However, the imaging-adjusted impacts for myeloma and prostate cancer were not different from those for other cancer types.

Restaging. Table 6 shows the impact of PET performed for cancer restaging. For this indication, the impact of PET on intended management showed the widest variation by cancer type within a testing indication. PET studies in patients with connective tissue, nonmelanoma skin, and cervical cancers led to changes in intended management in about $25 \%$ of patients; this frequency was lower than that for other cancers (odds ratios $=0.53-0.69$ ). The lower frequency of change in management for these cancers persisted in the imaging-adjusted impact as well (range $=6.3 \%-10.5 \%$ ).

Detection of Suspected Recurrence. Table 7 summarizes the impact of PET performed for detection of suspected cancer recurrences. Suspected recurrences of ovarian and prostate cancers were by far the most frequent in our cohort. According to our primary definition of a change in intended management, patients with myeloma $(50.9 \%)$ and ovarian cancer $(44.5 \%)$ were more likely and those with kidney cancer (32.4\%) and stomach cancer (29.3\%) were less likely to have a change in management after PET. However, on the basis of the imaging-adjusted impact, the only cancer type for which a notable difference from other cancer types was seen was primary brain cancer; for the latter, a change in management occurred in $28.4 \%$ of patients (odds ratio $=1.73$ ).

\section{DISCUSSION}

The large number of patients enrolled in the NOPR presented an unprecedented opportunity to assess the relative impact of PET on intended patient management across a diversity of cancer types. Here, we report on the relative impact of PET on patients with 18 different types of known cancers for 3 distinct indications (initial staging, restaging, and detection of suspected recurrence). With the notable sole exception of multiple myeloma, there were no cancer types for which the impact of PET was consistently higher or lower 
TABLE 4

Summary by Testing Indication for All Cancer Types in NOPR

\begin{tabular}{|c|c|c|c|c|c|}
\hline Testing indication & $\begin{array}{l}\text { No. of } \\
\text { scans }\end{array}$ & $\begin{array}{c}\% \text { of cases } \\
\text { with change in } \\
\text { management* }\end{array}$ & $95 \% \mathrm{Cl}$ & $\begin{array}{l}\text { Imaging-adjusted } \\
\text { impact }(\%)^{\dagger}\end{array}$ & $95 \% \mathrm{Cl}$ \\
\hline Initial staging & 14,365 & 39.8 & $39.0-40.6$ & 13.4 & $12.8-13.9$ \\
\hline Restaging & 14,584 & 35.9 & $35.1-36.7$ & 12.6 & $12.0-13.1$ \\
\hline $\begin{array}{l}\text { Detection of suspected } \\
\text { recurrence }\end{array}$ & 11,914 & 38.5 & 37.6-39.3 & $18.8^{\ddagger}$ & $18.1-19.5$ \\
\hline Total & 40,863 & 38.0 & $37.6-38.5$ & 14.7 & $14.3-15.0$ \\
\hline
\end{tabular}

than average across all the indications studied. Moreover, there were only a small number of instances in which the change in management for a particular combination of cancer type and indication was significantly different from that for other cancer types studied for that indication. In our opinion, these few combinations are not likely to reflect major biologic or clinically meaningful differences in the ability of PET to influence patient management.

Our initial report of overall NOPR results (5) included data for PET scans obtained in some patients without documented cancer or with cancer of undocumented origin; these scans were obtained to determine whether a suspect lesion was cancer, to detect a primary tumor site in a patient with a presumed paraneoplastic syndrome, or to detect a primary tumor site in a patient with confirmed or strongly suspected metastatic disease. For the current analysis of the results for individual cancer types, we excluded data collected for these cancer diagnosis indications, because our goal was to assess the performance of PET in relation to cancer type and this goal required limiting the dataset to pathologically confirmed cancers of known origins. The impact of PET in an expanded cohort for these cancer diagnosis indications will be reported separately.

Our analysis of the imaging-adjusted impact of PET on intended management showed an overall change in 14.7\% of patients, with a modestly higher impact in the subset of patients referred for the detection of suspected recurrences. As noted earlier, this imaging-adjusted impact estimate can

TABLE 5

Impact of PET on Intended Management for Initial Staging by Cancer Type*

\begin{tabular}{|c|c|c|c|c|c|}
\hline Cancer type & $\begin{array}{l}\text { No. of } \\
\text { scans }\end{array}$ & $\begin{array}{c}\% \text { of cases } \\
\text { with change in } \\
\text { management }^{\dagger}\end{array}$ & $95 \% \mathrm{Cl}$ & $\begin{array}{l}\text { Imaging-adjusted } \\
\text { impact }(\%)^{\ddagger}\end{array}$ & $95 \% \mathrm{Cl}$ \\
\hline Prostate & 2,042 & 32.0 & $30.0-34.1$ & 13.5 & $12.0-15.0$ \\
\hline Stomach & 1,556 & 40.5 & $38.0-42.9$ & 14.8 & $13.1-16.6$ \\
\hline Pancreas & 1,491 & 39.2 & $36.8-41.7$ & 13.4 & $11.7-15.1$ \\
\hline Bladder & 1,461 & 39.9 & $37.4-42.4$ & 14.2 & $12.4-16.0$ \\
\hline Small cell lung & 1,082 & 43.3 & $40.4-46.3$ & 8.1 & $6.5-9.8$ \\
\hline Kidney & 895 & 41.1 & $37.9-44.3$ & 17.1 & $14.6-19.6$ \\
\hline Uterus & 746 & 41.6 & $38.0-45.1$ & 14.1 & $11.6-16.6$ \\
\hline Liver and intrahepatic bile ducts & 607 & 44.2 & $40.2-48.1$ & 14.3 & $11.5-17.1$ \\
\hline Connective tissue & 534 & 44.6 & $40.4-48.8$ & 15.9 & $12.8-19.0$ \\
\hline Nonmelanoma skin & 526 & 37.5 & $33.3-41.6$ & 10.1 & 7.5-12.6 \\
\hline Gallbladder & 409 & 41.3 & $36.5-46.1$ & 14.2 & $10.8-17.6$ \\
\hline Myeloma & 402 & 52.2 & $47.4-57.1$ & 10.2 & $7.2-13.2$ \\
\hline Ovary & 378 & 43.1 & $38.1-48.1$ & 16.1 & $12.4-19.8$ \\
\hline Cervix & 341 & 36.1 & $31.0-41.2$ & 9.1 & $6.0-12.1$ \\
\hline Other female genital & 331 & 37.8 & $32.5-43.0$ & 10.6 & $7.3-13.9$ \\
\hline All other & 1,564 & 40.4 & $38.0-42.8$ & 13.4 & $11.7-15.1$ \\
\hline Total & 14,365 & 39.8 & $39.0-40.6$ & 13.4 & 12.8-13.9 \\
\hline
\end{tabular}


TABLE 6

Impact of PET on Intended Management for Restaging by Cancer Type*

\begin{tabular}{|c|c|c|c|c|c|}
\hline Cancer type & $\begin{array}{l}\text { No. of } \\
\text { scans }\end{array}$ & $\begin{array}{c}\% \text { of cases } \\
\text { with change in } \\
\text { management }^{\dagger}\end{array}$ & $95 \% \mathrm{Cl}$ & $\begin{array}{l}\text { Imaging-adjusted } \\
\text { impact }(\%)^{\ddagger}\end{array}$ & $95 \% \mathrm{Cl}$ \\
\hline Ovary & 1,971 & 37.7 & $35.6-39.8$ & 13.0 & $11.6-14.5$ \\
\hline Prostate & 1,477 & 34.0 & $31.6-36.4$ & 13.5 & $11.7-15.2$ \\
\hline Small cell lung & 1,357 & 40.8 & $38.2-43.4$ & 14.2 & $12.4-16.1$ \\
\hline Bladder & 1,239 & 36.4 & $33.7-39.1$ & 13.6 & $11.7-15.5$ \\
\hline Uterus & 1,064 & 30.5 & $27.8-33.3$ & 11.7 & $9.7-13.6$ \\
\hline Pancreas & 1,021 & 38.3 & $35.3-41.3$ & 11.3 & $9.3-13.2$ \\
\hline Myeloma & 1,009 & 46.4 & $43.3-49.5$ & 10.8 & $8.9-12.7$ \\
\hline Kidney & 979 & 34.4 & $31.4-37.4$ & 12.8 & $10.7-14.9$ \\
\hline Stomach & 916 & 35.5 & $32.4-38.6$ & 13.4 & $11.2-15.6$ \\
\hline Connective tissue & 450 & 28.0 & 23.9-32.1 & 9.1 & $6.5-11.8$ \\
\hline Nonmelanoma skin & 363 & 23.1 & $18.8-27.5$ & 6.3 & $3.8-8.8$ \\
\hline Cervix & 353 & 26.9 & $22.3-31.5$ & 10.5 & $7.3-13.7$ \\
\hline Liver and intrahepatic bile ducts & 260 & 41.9 & $35.9-47.9$ & 16.2 & $11.7-20.6$ \\
\hline Leukemia & 229 & 36.7 & $30.4-42.9$ & 14.8 & $10.2-19.5$ \\
\hline Gallbladder & 215 & 38.6 & $32.1-45.1$ & 13.5 & 8.9-18.1 \\
\hline Thyroid & 203 & 34.5 & $27.9-41.0$ & 10.8 & $6.6-15.1$ \\
\hline All other & 1,478 & 33.2 & $30.8-35.6$ & 12.9 & $11.1-14.6$ \\
\hline Total & 14,584 & 35.9 & $35.1-36.7$ & 12.6 & 12.0-13.1 \\
\hline
\end{tabular}

*Specific cancer types are listed when there were at least 200 cases.

${ }^{\dagger}$ Defined as change from treatment to nontreatment or as change from nontreatment to treatment.

${ }^{\ddagger}$ No benefit from PET was assumed for cases with imaging plan before PET.

be considered a hypothetical lower boundary of the impact of PET, but the true impact is likely to be higher. This is because it has been amply documented that PET is generally more sensitive and specific than CT, MRI, or other imaging methods for the detection of cancer (on both a patient basis and a lesion basis) (8-11). Moreover, it has been shown that the improved accuracy of PET compared with conventional imaging methods leads to more frequent

TABLE 7

Impact of PET on Intended Management for Detection of Suspected Recurrence by Cancer Type*

\begin{tabular}{|c|c|c|c|c|c|}
\hline Cancer type & $\begin{array}{l}\text { No. of } \\
\text { scans }\end{array}$ & $\begin{array}{c}\% \text { of cases } \\
\text { with change in } \\
\text { management }^{\dagger}\end{array}$ & $95 \% \mathrm{Cl}$ & $\begin{array}{l}\text { Imaging-adjusted } \\
\text { impact }(\%)^{\ddagger}\end{array}$ & $95 \% \mathrm{Cl}$ \\
\hline Ovary & 2,160 & 44.5 & $42.4-46.6$ & 19.1 & $17.4-20.7$ \\
\hline Prostate & 1,790 & 39.4 & $37.2-41.7$ & 18.0 & $16.3-19.8$ \\
\hline Uterus & 1,059 & 38.8 & $35.9-41.7$ & 19.3 & $16.9-21.6$ \\
\hline Kidney & 1,003 & 32.4 & 29.5-35.3 & 18.2 & 15.9-20.6 \\
\hline Bladder & 878 & 36.7 & $33.5-39.9$ & 19.8 & $17.2-22.5$ \\
\hline Pancreas & 802 & 39.3 & $35.9-42.7$ & 22.1 & $19.2-24.9$ \\
\hline Stomach & 553 & 29.3 & $25.5-33.1$ & 15.2 & $12.2-18.2$ \\
\hline Small cell lung & 544 & 38.1 & $34.0-42.1$ & 20.2 & $16.8-23.6$ \\
\hline Myeloma & 373 & 50.9 & $45.9-56.0$ & 14.7 & $11.1-18.3$ \\
\hline Connective tissue & 366 & 34.7 & 29.8-39.6 & 15.8 & $12.1-19.6$ \\
\hline Cervix & 290 & 35.9 & $30.3-41.4$ & 16.9 & $12.6-21.2$ \\
\hline Thyroid & 253 & 33.2 & 27.4-39.0 & 17.0 & $12.4-21.6$ \\
\hline Primary brain & 222 & 40.5 & $34.1-47.0$ & 28.4 & $22.4-34.3$ \\
\hline Other female genital & 206 & 39.8 & $33.1-46.5$ & 17.5 & $12.3-22.7$ \\
\hline All other & 1,415 & 35.1 & $32.6-37.5$ & 19.4 & $17.3-21.4$ \\
\hline Total & 11,914 & 38.5 & $37.6-39.3$ & 18.8 & $18.1-19.5$ \\
\hline
\end{tabular}


upstaging or downstaging and, accordingly, to more frequent management changes.

The imaging-adjusted impact of PET seemed to show less variation across cancer types than did the primary nontreatment-treatment endpoint. The reasons for this finding are unclear. The NOPR did not collect information about whether and when other imaging procedures may have been performed before PET. Thus, we are unable to determine which of several possible circumstances might have led referring physicians to select another type of imaging as their intended management plan if PET was not available. Possible circumstances include situations in which PET was requested as the first imaging test instead of as an alternative imaging procedure, PET was requested after CT or MRI of one body region to evaluate the rest of the body (the alternative being to perform CT or MRI of the rest of the body), PET was requested immediately after inconclusive CT (the alternative being to perform MRI), or PET was requested for interval follow-up of previously inconclusive findings on CT or MRI (the alternative being to repeat those tests).

The NOPR data provide no direct insights into the factors that influence a referring physician to order PET during the continuum of care of a cancer patient. The practice-based nature of the NOPR data and our primary finding of little variation in impact across cancer types-despite the expectation that PET would be of limited value for some cancers, such as those that are typically considered to have relatively poor ${ }^{18}$ F-FDG avidity (e.g., prostate carcinoma (12)) — may indicate that referring physicians are quite selective in ordering PET.

To estimate the number of patients potentially eligible for participation in the NOPR, we obtained incidence data by cancer type for patients over age 65 from the United States Cancer Statistics for 2004 (the most recent year for which data are available) (13). These were compared with the numbers of NOPR PET scans in 2007 for the same cancer types for patients over age 65. Using this simple approximation, we estimated that for most cancer types, between $10 \%$ and $20 \%$ of patients participated in the NOPR. Our estimate ranged from a low of about $3 \%$ of prostate cancer patients to about $38 \%$ of ovarian cancer patients (data not shown).

\section{CONCLUSION}

We believe that the NOPR results show the impact of PET to be strikingly consistent for a wide range of cancers.
Accordingly, the use of PET in management for patients with known cancer should not be restricted by cancer type or testing indication.

\section{ACKNOWLEDGMENTS}

We thank the many individuals at the Academy of Molecular Imaging, American College of Radiology, American College of Radiology Imaging Network, Society of Nuclear Medicine, American Society of Clinical Oncology, and Centers for Medicare \& Medicaid Services who contributed to the development of the National Oncologic PET Registry. Funding for development of the National Oncologic PET Registry was provided by the Academy for Molecular Imaging, but the registry is otherwise self-supported by fees paid by participating PET facilities.

\section{REFERENCES}

1. Kelloff GJ, Hoffman JM, Johnson B, et al. Progress and promise of FDG-PET imaging for cancer patient management and oncologic drug development. Clin Cancer Res. 2005;11:2785-2808.

2. Centers for Medicare \& Medicaid Services, Department of Health \& Human Services. CMS Manual System. Pub 100-03 Medicare National Coverage Determinations. Transmittal 31. Available at: http://www.cms.hhs.gov/ Transmittals/downloads/R31NCD.pdf. Accessed October 15, 2008.

3. Tunis SR, Pearson SD. Coverage options for promising technologies: Medicare's 'coverage with evidence development.' Health Aff. 2006;25:1218-1230.

4. National Oncologic PET Registry. Available at: http://www.cancerpetregistry.org/. Accessed October 15, 2008.

5. Hillner BE, Siegel BA, Liu D, et al. Impact of positron emission tomography/ computed tomography and positron emission tomography (PET) alone on expected management of patients with cancer: initial results from the National Oncologic PET Registry. J Clin Oncol. 2008;26:2155-2161.

6. Hillner BE, Liu D, Coleman RE, et al. The National Oncologic PET Registry (NOPR): design and analysis plan. J Nucl Med. 2007;48:1901-1908.

7. Lindsay MJ, Siegel BA, Tunis SR, et al. The National Oncologic PET Registry: expanded Medicare coverage for PET under coverage with evidence development. AJR. 2007;188:1109-1113.

8. Antoch G, Saoudi N, Kuehl H, et al. Accuracy of whole-body dual-modality fluorine-18-2-fluoro-2-deoxy-D-glucose positron emission tomography and computed tomography (FDG-PET/CT) for tumor staging in solid tumors: comparison with CT and PET. J Clin Oncol. 2004;22:4357-4368.

9. von Schulthess GK, Steinert HC, Hany TF. Integrated PET/CT: current applications and future directions. Radiology. 2006;238:405-422.

10. Bar-Shalom R, Yefremov N, Guralnik L, et al. Clinical performance of PET/CT in evaluation of cancer: additional value for diagnostic imaging and patient management. J Nucl Med. 2003;44:1200-1209.

11. Gambhir SS, Czernin J, Schwimmer J, Silverman DH, Coleman RE, Phelps ME. A tabulated summary of the FDG PET literature. J Nucl Med. 2001;42(5 suppl):1S-93S.

12. Schöder H, Larson SM. Positron emission tomography for prostate, bladder, and renal cancer. Semin Nucl Med. 2004;34:274-292.

13. National Program of Cancer Registries (NPCR), Centers for Disease Control and Prevention, Department of Health and Human Services. United States Cancer Statistics (USCS): 1999-2004 Cancer Incidence and Mortality Data. Available at: www.cdc.gov/uscs. Accessed October 15, 2008. 